\title{
Atypical presentation of crusted (Norwegian) scabies
}

\author{
C. Del Borgo $^{1} \cdot$ V. Belvisi $^{1} \cdot$ T. Tieghi $^{1} \cdot$ Claudio M. Mastroianni $^{1}$
}

Received: 1 February 2015 / Accepted: 20 March 2015 / Published online: 29 March 2015

(C) Springer-Verlag Berlin Heidelberg 2015

Fig. 1 Clinical presentation of crusted scabies on the hands and nails. a, b Hyperkeratotic lesions and thick skin. c, d Full recovery after treatment

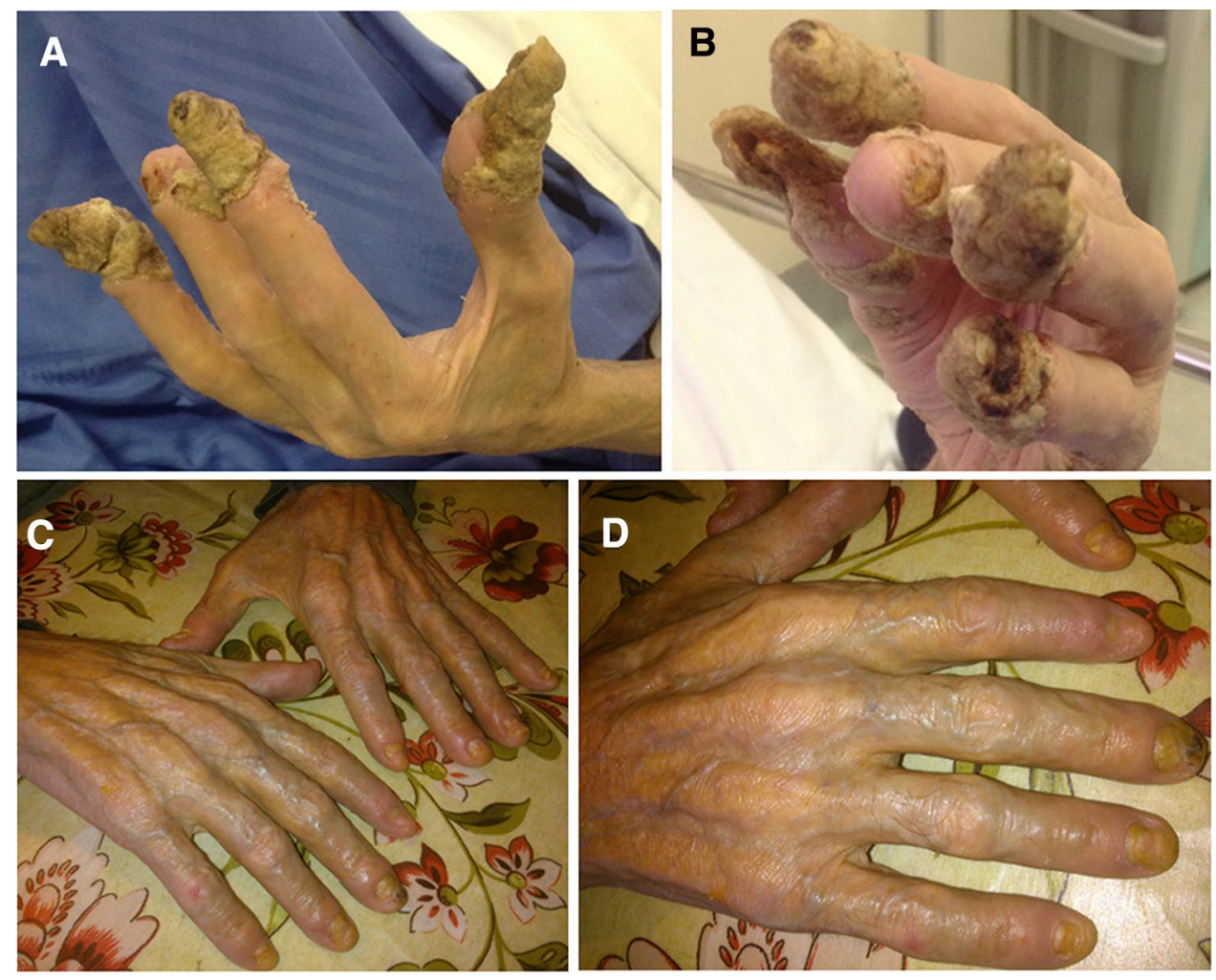

A 67-year-old HIV-infected man presented with hyperkeratotic lesions on the hands and nails (Fig. 1a, b). He had a history of HIV-associated encephalopathy with persistent

Claudio M. Mastroianni

claudio.mastroianni@uniroma1.it

1 Infectious Disease Unit, SM Goretti Hospital, Sapienza University, Via Canova 4, 04100 Latina, Italy cognitive and motor deficits. HIV seropositivity was discovered in 1998 (CDC Stage C3). The patient had undetectable HIV load and CD4 count $=166 / \mathrm{mmc}$ load, following a PI-based therapy.

Differential diagnosis included exacerbation of psoriasis, atopic eczema, paraneoplastic syndrome or mycotic infection. Examination of skin scrapings from crusted plaques revealed the presence of mites. Localized crusted (Norwegian) scabies was diagnosed. The patient was treated with 
topical permethrin ( $5 \%$ ) every 3 days for 2 weeks in combination with emollients and antikeratolytics. Oral ivermectin $(200 \mu \mathrm{g} / \mathrm{kg} / \mathrm{dose})$ was also given in three doses (days 1 , 2 and 8) [1]. After 1 month, there was a complete recovery of lesions (Fig. 1c, d).

Crusted (Norwegian) scabies is a rare, highly contagious skin parasitic infestation. The disease is usually reported in immunocompromised patients, such as people with HIV/ AIDS, malignancies or those receiving immunosuppressive drugs [2]. Despite the severity of the disease, there is significant variability in the clinical presentation [3]. Crusted scabies is usually generalized in various parts of the body surface, but localized forms may also occur [4]. Progressively overlapping layers of hyperkeratosis and thick skin may produce the unusual clinical manifestations as seen in this patient. Thus, clinicians should be vigilant about localized presentation of crusted scabies especially in immunosuppressed patients [5]. A delay in diagnosis and treatment leads to dissemination of the infestation with increasing risk of sepsis and death, as well as scabies nosocomial outbreaks.
Conflict of interest None to declare related to this study.

\section{References}

1. Currie BJ, McCarthy JS. Permethrin and ivermectin for scabies. N Engl J Med. 2010;362:117-25.

2. Yélamos O, Mir-Bonafé JF, López-Ferrer A, Garcia-Muret MP, Alegre M, Puig L. Crusted (Norwegian) scabies: an under-recognized infestation characterized by an atypical presentation and delayed diagnosis. J Eur Acad Dermatol Venereol. 2014. doi:10.1111/jdv.12867 (Epub ahead of print).

3. Davis JS, McGloughlin S, Tong SY, Walton SF, Currie BJ. A novel clinical grading scale to guide the management of crusted scabies. PLoS Negl Trop Dis. 2013;7:e2387. doi:10.1371/journal.pntd.0002387.

4. Porras-Luque JI, Valks R, Daudén E, Fernández-Herrera J. Localized crusted scabies in a patient with acquired immunodeficiency syndrome. Acta Derm Venereol. 1997;77:326-7.

5. Roberts LJ, Huffam SE, Walton SF, Currie BJ. Crusted scabies: clinical and immunological findings in seventy-eight patients and a review of the literature. J Infect. 2005;50:375-81. 